Lopes, C. Familias formadas por parejas del mismo sexo y el Codigo Civil y Comercial de la Nación. Derecho y Ciencias Sociales. Octubre 2018. № 19. (Las familias y el derecho de las familias a dos años de vigencia del Código Civil y Comercial) Pgs 22-44. ISNN 1852-2971. Instituto de Cultura Jurídica y Maestría en Sociología Jurídica. FCJ y S. UNLP

\title{
Familias formadas por parejas del mismo sexo y el Código Civil y Comercial de la Nación
}

\section{Same-gender families and the National aCivil and Commercial Code}

Cecilia Lopes ${ }^{\bullet}$

\section{Resumen}

El trabajo aborda las innovaciones en materia de familias con parejas del mismo sexo por parte del CCyC. A tal fin se realiza un breve recorrido normativo, no agotándose el análisis solamente en el CCyC sino abordando los micros sistemas previos y actuales con los que conviven y hacen posible pensar a las familias en plural, analizando las distintas fuentes de filiación contempladas por el derecho argentino, las cuales responden a diferentes formas de organización familiar. Se señalan, además, tanto las realidades pendientes de regulación así como también hitos de la jurisprudencia en relación a la resolución de casos tanto ante la existencia o (in)existencia de normativa y algunos desafíos pendientes.

Palabras claves: Homoparentalidad; Diversidad; Familias; Filiación

\begin{abstract}
:
This paper addresses the innovations included in the new Civil and Commercial Code in terms of same-gender families. For this purpose a brief account is made, not only of the regulations in the Code but of the previous microsystems which coexist with the current ones as well. This particular dynamic males plurality in families possible. Therefore, an analysis of different sources of filiation in Argentinian law -which respond to different forms of family organizations- is carried out. Thorughout thus work both realities that still lack of regulations and jurisprudencial milestones as regards solving cases with or with out regulations are pointed out
\end{abstract}

Key words: Diversity; families; homparentality; filiation

\footnotetext{
- Abogada, docente de Derecho Civil V (Derecho de Familia y Sucesiones), FCJyS UNLP, coordinadora del Programa de Extensión “Diversidad familiar y derecho de familias” FCJyS UNLP.: cecilopes@ yahoo.com

Recibido: 12 /3/ 2018 - Aceptado con correcciones: 5/9/2018
} 
Lopes, C. Familias formadas por parejas del mismo sexo y el Codigo Civil y Comercial de la Nación. Derecho y Ciencias Sociales. Octubre 2018. № 19. (Las familias y el derecho de las familias a dos años de vigencia del Código Civil y Comercial) Pgs 22-44. ISNN 1852-2971. Instituto de Cultura Jurídica y Maestría en Sociología Jurídica. FCJ y S. UNLP

\section{Familias formadas por parejas del mismo sexo y el Código Civil y Comercial de la} Nación

Cecilia Lopes

\section{Introducción}

Cuando hace 15 años una autora francesa explicaba cuatro maneras distintas por las que era posible arribar a una familia homoparental, poco podían imaginarse los avances que en nuestro país se darían en torno a cada una de ellas. Se señalaba en ese momento que

"La familia homosexual, es decir, los padres homosexuales y sus hijos, puede configurarse a través de cuatro fórmulas: puede surgir 1) a raíz de una nueva formación familiar mixta con un compañero del mismo sexo tras una unión heterosexual; puede proceder 2) de un sistema de coparentalidad en el que gays y lesbianas que viven solos o en pareja se ponen de acuerdo para tener un hijo que se criará entre las dos unidades familiares, materna y paterna, la primera exclusivamente femenina y la segunda sólo masculina; también se puede establecer 3) gracias a la adopción de un niño o 4) al nacimiento de un hijo engendrado con técnicas de procreación asistida (PA), a través de la inseminación artificial con donante o madre de alquiler." (CADORET A., 2003:17).

Si bien por ese entonces escribíamos sobre algunos aspectos de la temática (LOPES y PIETRA, 2005 y LOPES 2005), la gran novedad por la que atraviesa nuestro país es la inclusión de esta forma de organización familiar como una opción entre otras en un contexto de pluralidad, donde la normativa del nuevo Código Civil y Comercial regula relaciones jurídicas de familias en plural en condiciones de igualdad formal, aunque con algunas dificultades al momento de concretar, en el plano real, el proyecto parental escogido.

Hablar hoy en plural de las familias en Argentina es sin lugar a dudas el resultado de un intenso y certero reclamo reivindicativo por la igualdad que encabezó con absoluta firmeza el colectivo LGTBIQ desde distintos frentes y con diferentes herramientas. Debe destacarse, como conquista de ese movimiento y antecedente legislativo que cimienta de manera muy potente la transformación de la que hoy damos cuenta a la Ley 26.618, conocida como la Ley de matrimonio igualitario, sancionada en julio de $2010{ }^{1}$

\footnotetext{
${ }^{1}$ Debe destacarse que antes de la sanción de la Ley 26.618, varias sentencias resolvieron favorablemente amparos presentados en diferentes lugares del país, permitiendo que parejas del mismo sexo contrajeran matrimonio a partir de la declaración de inconstitucionalidad de los arts. 172 y 188 del Código anterior, entro otros: Juzg. $1^{\text {a }}$ Inst. Cont., Adm. y Trib. No 15 de C.A.B.A., sent. del 10/11/11 en autos "F. A. c/ GCBA s/

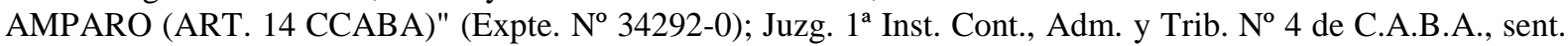
del 22/02/2010 en autos "B., D. A y otros s/ amparo" (Expte. No 36117/0), Juzg. $1^{\text {a }}$ Inst. Cont., Adm. y Trib. No 13 de C.A.B.A., sent. del 19/03/2010 en autos "CM y otro c/ GCBA s/ Amparo (Art. 14 CCABA)" (Expte. No 36410/0); Trib. Oral en lo Crim. № 2 de La Plata, sent. del 17/5/2010 en autos "DV y PCP s/ Amparo" (Expte. $\left.\mathrm{N}^{\mathrm{3}} 3604 / \mathrm{D}-2037\right)$. La estrategia judicial fue clave en la posterior aprobación de la norma.
} 
Lopes, C. Familias formadas por parejas del mismo sexo y el Codigo Civil y Comercial de la Nación. Derecho y Ciencias Sociales. Octubre 2018. № 19. (Las familias y el derecho de las familias a dos años de vigencia del Código Civil y Comercial) Pgs 22-44. ISNN 1852-2971. Instituto de Cultura Jurídica y Maestría en Sociología Jurídica. FCJ y S. UNLP

Los efectos de dicha norma, que solamente modificó en el plano normativo la posibilidad de acceder al matrimonio civil a parejas del mismo sexo, se expandieron a otros ámbitos. Permitió amparar jurídicamente vínculos filiales entre madres, padres, hijos e hijas alcanzados a través de la adopción por parte de una pareja casada o en el caso de madres, a través de la aplicación por analogía de la presunción de paternidad del marido de la madre, regulada por el derogado Código Civil (art. 243), a parejas de mujeres que accedían a una técnica de reproducción humana asistida (KEMELMAJER DE CARLUCCI, HERRERA y LAMM, 201, GIL DOMINGUEZ, 2012).

Este trabajo tiene por objeto precisar los contornos del escenario normativo en el que hoy se concretan los proyectos parentales por parte de parejas del mismo sexo, destacando algunas barreras que allí todavía continúan obstaculizando el acceso y/o el ejercicio de dicha parentalidad. La elección de esta perspectiva de análisis parte del reconocimiento de la particular importancia que asume el plano normativo en la propia consolidación de las familias, al habilitar en muchos casos la ley proyectos familiares que crecen únicamente en la intimidad de los hogares. Puede verse claramente como ejemplo de ello lo que sucedía con la adopción antes de la ley de matrimonio igualitario: como no podían casarse adoptaba uno solo de los miembros de la pareja, dejando desprotegido el vínculo que se generaba con el otro. Con la sanción de la norma los primeros casos fueron adopciones por parte del cónyuge del adoptante, completando en el plano legal el vínculo que ya existía en el plano real.

Pero además, este análisis también posibilitará formular algunas consideraciones respecto a algunas realidades familiares que reclaman regulación, ya sea para acceder en condiciones de igualdad a la parentalidad o, habiendo ya accedido, para ser amparados jurídicamente en tanto no han integrado hasta ahora la esfera legal. Por último, se esbozaran algunas ideas que pueden ser el puntapié inicial para análisis en otros sentidos que aborden nuevos desafíos en el escenario de la pluralidad de familias.

\section{Las filiaciones en el Código Civil y Comercial}

El vínculo jurídico que une a las personas con sus padres o madres puede ser atado de manera plural en tanto el nuevo plexo normativo regula tres fuentes filiatorias distintas: la naturaleza, la adopción y las técnicas de reproducción humana asistida (en adelante TRHA). Señala el art. 558 en torno a este tema que

La filiación puede tener lugar por naturaleza, mediante técnicas de reproducción humana asistida, o por adopción. La filiación por adopción plena, por naturaleza o por técnicas de reproducción 
Lopes, C. Familias formadas por parejas del mismo sexo y el Codigo Civil y Comercial de la Nación. Derecho y Ciencias Sociales. Octubre 2018. № 19. (Las familias y el derecho de las familias a dos años de vigencia del Código Civil y Comercial) Pgs 22-44. ISNN 1852-2971. Instituto de Cultura Jurídica y Maestría en Sociología Jurídica. FCJ y S. UNLP

humana asistida, matrimonial y extramatrimonial, surten los mismos efectos, conforme a las disposiciones de este Código. Ninguna persona puede tener más de dos vínculos filiales, cualquiera sea la naturaleza de la filiación.

La distinción de las fuentes filiatorias permite abordar la particularidad del lazo paterno o materno filial en la especificidad de sus características, con efectos jurídicos acordes a la mejor protección de los derechos y obligaciones de las partes.

Repárese que hasta 2015 nuestro país no contaba con una solución legal frente a aquellos vínculos filiales que se gestaban a través de las TRHA, aplicándose analógicamente lo que estaba prescripto para los supuestos de parentesco por "consanguinidad" o filiación biológica. Esa interpretación afectaba de manera particular los derechos de las familias formadas por parejas del mismo sexo, en las que el elemento carnal o biológico aparecía debilitado frente al peso asumido por el elemento volitivo, configurado por el deseo de convertirse en madres o padres.

Una de las primeras sentencias dictadas luego de la ley de matrimonio igualitario abordando este tema, fue la que dirimió el conflicto suscitado a partir del nacimiento de un niño a través de la TRHA conocida como método R.O.Pa.- TRHA exclusiva de las parejas de mujeres, donde acudiendo a la fecundación in vitro una de ellas aporta los óvulos y la otra es la gestante y cuenta con la participación biológica de ambas- y la denegatoria del Registro Civil de inscribir su filiación como hijo de las dos mujeres, cónyuges, que accedieron a dicha técnica.

La solución para ese caso terminó apoyándose, en definitiva, en la filiación biológica. Más allá de reconocer la importancia de la voluntad procreacional y prescribir que

“...la situación descripta en el escrito de inicio revela una clara discriminación por la condición sexual de la pareja y una grave vulneración de su derecho a la identidad y a la autonomía personal..."

la magistrada finaliza autorizando

“...a las autoridades del Registro Civil de Estado y Capacidad de las Personas de la Capital Federal a que procedan de inmediato a rectificar la inscripción del nacimiento del menor M. A. P. ... debiendo consignarse que también es hijo de M. del P. C.- en virtud del natural reconocimiento que exige como su ovo madre, reconociendo así su realidad

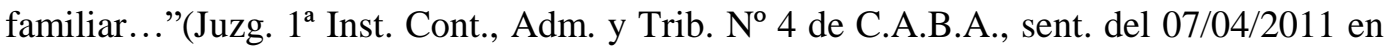
autos “M. del P. C. y otra c. GCBA", AR/JUR/15967/2011.)

Es interesante pensar qué habría sucedido en ese caso si la cónyuge no gestante no hubiera sido también "ovo madre”, ¿hubiera llegado a la misma solución?. 
Lopes, C. Familias formadas por parejas del mismo sexo y el Codigo Civil y Comercial de la Nación. Derecho y Ciencias Sociales. Octubre 2018. № 19. (Las familias y el derecho de las familias a dos años de vigencia del Código Civil y Comercial) Pgs 22-44. ISNN 1852-2971. Instituto de Cultura Jurídica y Maestría en Sociología Jurídica. FCJ y S. UNLP

Los fundamentos que acompañaron el Anteproyecto de Reforma al CCyCN establecían por aquel entonces que con el texto propuesto en materia de filiación,

"Se pretende zanjar los debates doctrinales y jurisprudenciales que se generaron con la incorporación del matrimonio de personas del mismo sexo, introduciendo modificaciones sustanciales a los fines de que el sistema filial esté en plena coincidencia con la nueva conceptualización del matrimonio." (Fundamentos CCyC)

Sin embargo, en términos de diversidad familiar y parejas del mismo sexo, los cambios alcanzan también a quienes no contraigan matrimonio. Cuando el nuevo cuerpo normativo regula los efectos jurídicos a las uniones convivenciales, por ejemplo la posibilidad de adoptar conjuntamente (art. 599), conceptualiza este tipo de uniones como aquellas basadas en relaciones afectivas de carácter singular, pública, notoria, estable y permanente de dos personas que conviven y comparten un proyecto de vida común, sean del mismo o de diferente sexo (art. 509).

Sucede que la heteronormatividad como mandato en la constitución de una familia, preferentemente fundada a partir del matrimonio, cedió paso a la pluralidad (JELIN, 2017) y este paradigma se expande a todas las formas familiares, matrimoniales o no. Y esta puja por acceder en condiciones de igualdad al derecho humano a formar una familia la actualiza día a día la lucha y enfrenta nuevos desafíos.

La distinción de fuentes filiales y la regulación de sus especificidades permite analizar de mejor manera el lugar de las parejas del mismo sexo en cada una de ellas en pos de resguardar los lugares que cada integrante ocupa en esa parentalidad que conecta a madres, padres, hijos e hijas. Ese lugar es ocupado también por otras alternativas familiares, reguladas o no, que erosionan el mismo concepto de diversidad sobre el que se cree asentado el modelo familiar: ¿qué pasa si quienes desean postularse como aspirantes a la adopción son una pareja de amigos o amigas, convivan o no? ¿por qué ese proyecto parental sólo se reserva para otras fuentes filiales? ¿qué pasa con los proyectos parentales que relacionan TRHA y la posibilidad de que la voluntad procreacional sea de más de dos personas?. Por otra parte, otro análisis posible es la diferencias de género que dentro de las familias incluso formadas por parejas del mismo sexo se dan en la realidad y como perjudican a las mujeres. (ANDRIOLA y LOPES, 2018).

Por último, en el contexto descripto es posible preguntarse qué parejas del mismo sexo acceden a una TRHA y quienes, por cuestiones económicas, tienen vedado ese camino. Lo mismo en la adopción: ¿qué pasa si en un contexto de informalización del mercado laboral el postulante no puede acreditar su ocupación o sus ingresos? 
Lopes, C. Familias formadas por parejas del mismo sexo y el Codigo Civil y Comercial de la Nación. Derecho y Ciencias Sociales. Octubre 2018. № 19. (Las familias y el derecho de las familias a dos años de vigencia del Código Civil y Comercial) Pgs 22-44. ISNN 1852-2971. Instituto de Cultura Jurídica y Maestría en Sociología Jurídica. FCJ y S. UNLP

Lo expuesto hasta aquí, siguiendo a GUERRA, demuestra que:

“...la familia como dice Heidi Hartmann, es un terreno de lucha política de género y de clase. Y en esa disputa ideológica la Iglesia Católica se pronuncia nuevamente contra el derecho a decidir sobre el propio cuerpo y la propia sexualidad. Derecho indispensable si pretendemos construir lazos, relaciones, familias y sociedades que respeten los derechos humanos de todas y todos..." (GUERRA, 2010, 14).

\section{2.a. Para empezar, dos vínculos.}

El Código optó por no regular la pluriparentalidad, tema que no analizaremos en este trabajo. En tal sentido, establece expresamente en el art. 558 que la filiación sólo puede dar origen a dos vínculos, como máximo: o madre y padre o dos madres o dos padres. Ello surge como consecuencia de la regla general de doble vínculo filial, el art. 578 el cual establece: "Si se reclama una filiación que importa dejar sin efecto una anteriormente establecida, debe previa o simultáneamente, ejercerse la correspondiente acción de impugnación”. En palabras de GIL DOMÍNGUEZ (2016, 51), no se abordaron jurídicamente los desafíos que genera el poliamor, entendido como toda relación amorosa y/o filiatoria duradera de la cual participan más de dos personas y que, en el ámbito de la filiación, se expresan en términos registrales civiles cuando más de dos personas ejercen plenamente su voluntad procreacional, gozando los derechos y cumpliendo los deberes que de ésta surgen.

Se ha señalado que

Ante la multiplicidad de opciones que los seres humanos tenemos de formar familia, parece lógico deducir que las respuestas legales también se diversifiquen. Aún cuando en muy poco tiempo la legislación familiar argentina haya avanzado mucho más de lo que jamás haya hecho, guiada por los principios de libertad y autonomía personal, aún queda mucho camino por recorrer. Sí, por un lado, es cierto que los principios de heteronormatividad, bionormatividad y binormatividad siguen fuertemente enraizados en las disposiciones legales filiatorias, al mismo tiempo, es posible percibir como hoy el número dos trastabilla, al borde del precipicio, haciendo equilibrio para no caer" (DE LORENZI, 2017, 273).

De acuerdo a la autora, una de las razones es el desarrollo técnico reproductivo, al permitir separar sexualidad de reproducción como así también reproducción y paternidad/maternidad.

Sin embargo, la pluriparentalidad puede verse en la realidad. Registramos en nuestro país dos casos resueltos administrativamente aunque durante la vigencia del Código Civil anterior. En ambos casos, una pareja de mujeres decidió llevar adelante su proyecto parental junto a un hombre que aporta sus gametos, no en calidad de donante sino con la deliberada 
Lopes, C. Familias formadas por parejas del mismo sexo y el Codigo Civil y Comercial de la Nación. Derecho y Ciencias Sociales. Octubre 2018. № 19. (Las familias y el derecho de las familias a dos años de vigencia del Código Civil y Comercial) Pgs 22-44. ISNN 1852-2971. Instituto de Cultura Jurídica y Maestría en Sociología Jurídica. FCJ y S. UNLP

intención de convertirse en el padre del niño que iba a nacer y que tendría, a su vez, dos mamas. Las decisiones administrativas fueron de los Registros Civiles de la provincia de Buenos Aires y de Ciudad Autónoma de Buenos Aires en el año 2015.

Como señala HERRERA, dentro de la variedad de familias en plural, “...no se descarta la existencia de una en la que una tercera persona o pareja mantenga vínculos con el niño, que aunque jurídicamente no se traduzcan en un vínculo filial, en virtud de que se conserva la regla del doble vínculo, pueden sí dar lugar a derechos y obligaciones". (2014:456). La autora ejemplifica con un precedente jurisprudencial cordobés del año 2010 donde se dispuso un régimen de comunicación a favor de la ex pareja lesbiana de la madre biológica de un niño, fruto de una inseminación artificial con semen de un varón unido también en pareja homosexual (JFam. 4 de Córdoba, sentencia del 28/06/2010 en autos “ASG c/ MVS y Otro s/ Medidas urgentes.).

Consecuentemente, la aplicación estricta del art. 558 no puede aislarse del mandato interpretativo dispuesto por los arts. 1, 2 y 3 del CCyC. De esta forma, puede suceder que de acuerdo a las circunstancias fácticas y concretas de un caso particular, un tercer (o posterior) vínculo pueda acarrear efectos jurídicos determinados: desde la comunicación o el deber alimentario hasta el corrimiento de la prohibición y el establecimiento de la filiación. Dos ejemplos de la realidad podrán dar cuenta de ello.

En primer lugar, es lo que ocurrió en el primer caso en que se planteó judicialmente el cruce entre pluriparentalidad y TRHA. Se trata de un proyecto parental de una mujer que aporta sus gametos y gesta y un matrimonio de dos varones, dónde uno de los dos aporta sus gametos. Al momento de prestar el consentimiento informado a la TRHA, lo hicieron los tres referenciando el de cada uno con el de los otros dos. Una vez nacida la niña, al momento de registrar su filiación el Registro Civil deniega la triple filiación pretendida razón por la cual se inicia el correspondiente proceso judicial. La sentencia, no firme al momento de redacción de este trabajo, después de analizar los hechos y el derecho aplicable decide:

"I.- Hacer lugar a la demanda decretando en el caso concreto la inconstitucionalidad y anticonvencionalidad del art. 558 último párrafo del $\mathrm{CCyCN}$ en este caso concreto, en cuanto no reconoce la voluntad procreacional mediante el consentimiento informado de más de dos personas; ordenando inscribir la filiación de A.C. como hija de M.F.C., J.C. y C.S.S. II.- Emplazar a los Sres. J.C. y C.S.S., como padres de A.C. III.- Autorizar a A.C. a sumar los apellidos de sus padres por lo que a partir de la presente deberá ser anotada ante el Registro del Estado Civil y Capacidad 
Lopes, C. Familias formadas por parejas del mismo sexo y el Codigo Civil y Comercial de la Nación. Derecho y Ciencias Sociales. Octubre 2018. № 19. (Las familias y el derecho de las familias a dos años de vigencia del Código Civil y Comercial) Pgs 22-44. ISNN 1852-2971. Instituto de Cultura Jurídica y Maestría en Sociología Jurídica. FCJ y S. UNLP

de las Personas como A.C.C.S...” (Juzg. Flia. 2 Mar del Plata, fecha 24/11/2017 dictada en autos C.M.F. y otros S/ MATERIA A CATEGORIZAR) ${ }^{2}$

En segundo lugar y desde otra óptica, el cruce de pluriparentalidad con adopción también posee antecedentes jurisprudenciales. Se trató de un caso donde en el marco de una adopción de integración, la familia sostuvo el deseo y el acuerdo de todos sus integrantes (niña, madre, padre y padre afín que pretende la adopción) de que la sentencia a dictarse no extinga, sustituya o restrinja vínculos, sino todo lo contrario, ampliarlos mediante la integración de un tercero que no fue primigeniamente parte de la familia. Acogida favorablemente la pretensión adoptiva, requerida la magistrada interviniente de aclaración a los efectos registrales del vínculo filiatorio creado dispone:

"En virtud de lo peticionado, líbrese oficio al Registro Civil para que proceda a inmovilizar el acta de nacimiento original de la niña ... y se proceda a confeccionar una nueva inscripción de nacimiento con los recaudos ... debiendo surgir inequívocamente del cuerpo del acto su triple filiación”. (Juzg. Flia 4 La Plata, 20/02/2017, BAJM s/ adopción acciones vinculadas,)

Como puede observarse, la prohibición del art. 558 leída a la luz de las circunstancias fácticas y concretas de un caso particular puede tornarse, por distintas estrategias, inaplicable.

\section{2. b. La filiación por naturaleza.}

La filiación por naturaleza está regulada como la respuesta jurídica a la situación donde una pareja heterosexual, de manera natural, alcanza el embarazo y posterior nacimiento de sus hijos. No hay aquí necesidad de la ciencia.

Según el art. 565 del nuevo Código, la maternidad se establece con la prueba del nacimiento y la identidad del nacido; la constancia del parto le hará atribuible a quien ha parido ese vínculo jurídico. El sistema normativo privilegia la capacidad gestante de la persona que da a luz con independencia de su género autopercibido,, por ello hablar de maternidad y mujer en un país con Ley de Identidad de Género (Ley 26.743), aún dentro de filiación por naturaleza, deja situaciones por fuera de la regulación. ${ }^{3}$

El otro vínculo jurídico queda supeditado al estado civil de quien dio a luz.

$\mathrm{Si}$ se trata de un matrimonio, ese otro vínculo tradicionalmente asociado a la paternidad se presume. Sin embargo, a partir de la posibilidad de que las personas puedan

\footnotetext{
${ }^{2}$ Esta sentencia se encuentra al momento de la elaboración de este trabajo en proceso de revisión por la Alzada en virtud de la apelación interpuesta por representantes del Ministerio Público.

${ }^{3}$ Resulta interesante a tal fin, la nota"Nació la hija del primer hombre embarazado de la Argentina", Infobae 19 de Diciembre de 2013, https://www.infobae.com/2013/12/19/1532000-nacio-la-hija-del-primer-hombreembarazado-la-argentina/.
} 
Lopes, C. Familias formadas por parejas del mismo sexo y el Codigo Civil y Comercial de la Nación. Derecho y Ciencias Sociales. Octubre 2018. № 19. (Las familias y el derecho de las familias a dos años de vigencia del Código Civil y Comercial) Pgs 22-44. ISNN 1852-2971. Instituto de Cultura Jurídica y Maestría en Sociología Jurídica. FCJ y S. UNLP

casarse con independencia de su sexo, el Código regula en estos casos el segundo vínculo como filiación presumida por la ley, pudiendo derivar en el padre o la otra madre del recién nacido.

El art. 566 establece "Excepto prueba en contrario, se presumen hijos del o la cónyuge los nacidos después de la celebración del matrimonio y hasta los trescientos días posteriores a la interposición de la demanda de divorcio o nulidad del matrimonio, de la separación de hecho o de la muerte”. Frente a la situación de dos mujeres casadas, dónde una da a luz, la maternidad de ambas será determinada por la ley: una a partir del alumbramiento y la otra a partir de su matrimonio con aquella.

Como quedó establecido, esto es lo que ocurría antes del nuevo Código y después de la sanción de la Ley de matrimonio igualitario, ya sea en relación con hijos e hijas que nacieron en ese período de tiempo en el marco de un matrimonio de mujeres o que hubieran nacido antes, en razón de la ampliación que formuló el Decreto 1006/2012 y la posterior norma transitoria de aplicación del Código Civil y Comercial de la Nación.

El mencionado decreto fue promovido por organizaciones defensoras de los derechos de las familias LGTBIQ. El art. $1^{\circ}$ dispusó la posibilidad de acceso a un trámite administrativo para completar la inscripción del nacimiento de niños menores de 18 años de edad de matrimonios conformados por dos mujeres y nacidos con anterioridad a la sanción de la Ley $\mathrm{N}^{\mathrm{o}} 26.618$.

A su vez, la norma transitoria tercera del CCyCN amplió la posibilidad de inscripción a aquellos niños y niñas que, por razón de la falta de matrimonio de sus progenitores, no fueron alcanzados con el beneficio del Dec. 1006/2012. Dice la norma:

"Los nacidos antes de la entrada en vigencia del Código Civil y Comercial de la Nación por técnicas de reproducción humana asistida son hijos de quien dio a luz y del hombre o la mujer que también ha prestado su consentimiento previo, informado y libre a la realización del procedimiento que dio origen al nacido, debiéndose completar el acta de nacimiento por ante el Registro Civil y Capacidad de las Personas cuando sólo constara vínculo filial con quien dio a luz y siempre con el consentimiento de la otra madre o del padre que no figura en dicha acta." (Capítulo 2 del Título $\mathrm{V}$ del Libro Segundo del Código Civil y Comercial de la Nación).

Sin embargo, la legislación actual nos permite avanzar en la conceptualización de esos vínculos, haciéndolos más precisos. Se parte para ello de entender que, en el caso de un matrimonio de mujeres, necesitaron los gametos de un tercero para concretar el embarazo, con ayuda de la ciencia o no, anónimo o no. En el caso de haber acudido a las TRHA y no contar con la voluntad procreacional de ambas expresada en el consentimiento pleno, libre e 
Lopes, C. Familias formadas por parejas del mismo sexo y el Codigo Civil y Comercial de la Nación. Derecho y Ciencias Sociales. Octubre 2018. № 19. (Las familias y el derecho de las familias a dos años de vigencia del Código Civil y Comercial) Pgs 22-44. ISNN 1852-2971. Instituto de Cultura Jurídica y Maestría en Sociología Jurídica. FCJ y S. UNLP

informado la filiación quedará determinada por naturaleza, tal como se viene expresando pero no contará con las protecciones jurídicas que la filiación por TRHA brinda a todas las partes. Por un lado, la protección del derecho a la información del nacido por TRHA (arts. 563 y 564) pero, por el otro, la protección del segundo vínculo determinado por presunción.

Sucede que en este caso no rige la regla del art. 577 que proclama la inadmisibilidad tanto de la impugnación de la filiación de los hijos nacidos mediante el uso de TRHA cuando haya mediado consentimiento previo, informado y libre a dichas técnicas, con independencia de quién haya aportado los gametos, como del reconocimiento y/o el ejercicio de acción de filiación o de reclamo alguno de vínculo filial respecto de éste.

Si nos encontramos dentro de la filiación por naturaleza extramatrimonial, es decir, cuando la madre que se ha determinado por el hecho del parto no está casada, el segundo vínculo jurídico se determina por la expresión de voluntad del padre a través del acto jurídico del reconocimiento. Requiere la existencia del vínculo biológico entre reconociente y reconocido razón por la cual se trata de situaciones de padres que reconocen a sus hijos cuya maternidad ya ha sido determinada.

El Código, en su art. 571, dispone el reconocimiento de un hijo resulta: a) de la declaración formulada ante el oficial del Registro del Estado Civil y Capacidad de las Personas en oportunidad de inscribirse el nacimiento o posteriormente; b) de la declaración realizada en instrumento público o privado debidamente reconocido; c) de las disposiciones contenidas en actos de última voluntad, aunque el reconocimiento se efectúe en forma incidental. Si la manifestación de voluntad generadora de filiación no es expresada espontáneamente, la determinación de la filiación extramatrimonial puede ser forzada, a través del proceso que se inicie a partir de la acción de reclamación establecida por el art. 582 y siguientes del Código.

\section{2. c. La filiación por adopción.}

La adopción se regula a partir del art. 594 como la institución jurídica que tiene por objeto proteger el derecho de niños, niñas y adolescentes a vivir y desarrollarse en una familia que le procure los cuidados tendientes a satisfacer sus necesidades afectivas y materiales, cuando éstos no le pueden ser proporcionados por su familia de origen. Los arts. 599, 600 y 601 disponen los requisitos para ser adoptantes, pudiendo tratarse de una persona sola o de ambos integrantes de un matrimonio o de una unión convivencial. 
Lopes, C. Familias formadas por parejas del mismo sexo y el Codigo Civil y Comercial de la Nación. Derecho y Ciencias Sociales. Octubre 2018. № 19. (Las familias y el derecho de las familias a dos años de vigencia del Código Civil y Comercial) Pgs 22-44. ISNN 1852-2971. Instituto de Cultura Jurídica y Maestría en Sociología Jurídica. FCJ y S. UNLP

Es aquí donde la realidad nos plantea un nuevo desafío: el Código no contempla otras relaciones entre adultos, como la amistad, para postularse como adoptantes de manera conjunta pero que, a la luz de la pluralidad de formas familiares actuales, podría ser replanteada como posibilidad si quienes se postulan cumplen con los objetivos buscados por la adopción: garantizarle a las personas menores de edad su derecho constitucional y convencional a vivir en familia.

Hoy, normativamente, el proyecto parental es de la pareja. Aún más, si contrajeron matrimonio o viven en unión convivencial deben adoptar conjuntamente. El art. 603 prevé como únicas excepciones aquellos casos donde uno de los cónyuges o convivientes haya sido declarado persona incapaz o de capacidad restringida y la sentencia le impide prestar consentimiento válido para la adopción o que los cónyuges estén separados de hecho. Entre los requisitos se destacan: a) Haber alcanzado la edad de veinticinco años de edad, salvo que el cónyuge o conviviente que adopta conjuntamente cumpla con este requisito. b) Diferencia de edad de 16 años entre adoptante y adoptado, salvo para el caso de adopción de integración. c) Residencia permanentemente en el país por un período mínimo de cinco años, salvo que se trate de personas de nacionalidad argentina o naturalizadas en el país. d) Inscripción en el registro de adoptantes.

Se regulan tres tipos de adopción: plena (arts. 624, 625 y 626), simple (627, 628 y 629) y de integración (arts. 630, 631, 632 y 633). De cualquier forma, los contornos de las diferencias se diluyen en tanto es posible la flexibilización de los tipos adoptivos en atención al principio del interés superior del niño. Consecuente con ello, el art. 621 establece "El juez otorga la adopción plena o simple según las circunstancias y atendiendo fundamentalmente al interés superior del niño. Cuando sea más conveniente para el niño, niña o adolescente, a pedido de parte y por motivos fundados, el juez puede mantener subsistente el vínculo jurídico con uno o varios parientes de la familia de origen en la adopción plena, y crear vínculo jurídico con uno o varios parientes de la familia del adoptante en la adopción simple...".

Consecuentemente, una pareja del mismo sexo puede optar por la adopción como forma de constituirse en familia con hijos y de la misma manera que con el Código anterior a partir de la Ley de Matrimonio Igualitario, puede tratarse de un matrimonio o, a partir del nuevo Código, de una unión convivencial. En nuestro país se han difundido producciones periodísticas que abordan la especificidad de la adopción por parejas del mismo sexo, señalando por ejemplo que su voluntad adoptiva es más amplia que la de las parejas de 
Lopes, C. Familias formadas por parejas del mismo sexo y el Codigo Civil y Comercial de la Nación. Derecho y Ciencias Sociales. Octubre 2018. № 19. (Las familias y el derecho de las familias a dos años de vigencia del Código Civil y Comercial) Pgs 22-44. ISNN 1852-2971. Instituto de Cultura Jurídica y Maestría en Sociología Jurídica. FCJ y S. UNLP

distinto sexo. ${ }^{4}$ Resulta de sumo interés avanzar en estudios más profundos sobre la temática, los que explorando esta hipótesis permitan conocer mejor las particularidades de esta forma familiar.

Por otra parte, debe destacarse también que es la única manera prevista por el ordenamiento jurídico interno para que una pareja de varones se convierta en padres, en tanto no se prevén TRHA que los incluya a ambos. Esta realidad ha generado jurisprudencia que prevé abordar la especificidad de parentalidad sustentada en la adopción, como por ejemplo la licencia extendida por paternidad en caso de que los adoptantes sean dos varones con fundamento en el derecho a la igualdad ante la ley y su correlato, la prohibición de no discriminación, a todos los seres humanos. ${ }^{5}$

\section{2.d. La filiación por TRHA.}

Esta tercera fuente filiatoria, cuya regulación ha sido incorporada, por fin, a nuestro ordenamiento jurídico a partir de la vigencia del nuevo $\mathrm{CCyC}$, es otra de las alternativas a la que, en general, una pareja del mismo sexo puede echar mano para convertirse en padres o madres. Para utilizar una definición legal, el art. $2^{\circ}$ de la Ley 26.862 del 26 de junio de 2013 sobre "Acceso integral a los procedimientos y técnicas médico-asistenciales de reproducción médicamente asistida", la cual dispone que se entiende por reproducción médicamente

\footnotetext{
${ }^{4}$ Resulta interesante a tal fin "Las barreras ocultas que sufren las parejas gay para adoptar" Revista Novicias, 10 de marzo de 2017, http://noticias.perfil.com/2017/03/10/las-barreras-ocultas-que-sufren-las-parejas-gay-paraadoptar-un-hijo/; "Los homosexuales son menos exigentes a la hora de adoptar" Diario La Nación, 18 de Agosto de 2014, https://www.lanacion.com.ar/1719017-los-homosexuales-son-menos-exigentes-a-la-hora-de-adoptar; sitios web visitados el 06/03/2018.

${ }^{5}$ Conf. Juzg. de Familia No 5 de Mar del Plata, autos: “A. L. B. Y A. I. O. S/ MATERIA A CATEGORIZAR (DECLARACION DE ADOPTABILIDAD) MP-11313-2015”, sent. de fecha 15/07/2015. Señala OBLIGADO que "Por tratarse el caso de un matrimonio igualitario y resultar hoy pretensos "padres adoptivos" (ambos varones) de los niños I y L, la dificultad que se nos impone en caso de hacer efectiva la licencia ya dispuesta por la suscripta en resolución de fs.125/127 es, ¿quién de los esposos gozará de la licencia extensa, el Sr. M o el Sr. $\mathrm{O}$ ? ya que en este entendimiento y conforme la normativa citada el grupo familiar compuesto por los Sres. M, O, y los niños L e I no tipificaría "un grupo familiar" que pudiera hacer efectivo la licencia alongada ya que no podrían solicitar ninguno de los Sres M.O, en razón de ser ambos, pretensos padres adoptivos varones. Es por ello que para el caso de I y L no podrán gozar del "tiempo mano de obra" (licencia extensa) de uno de sus pretensos padres adoptivos por el sólo hecho que no revisten el género mujer/madre tipificado en la ley 20744 ... Es clara la intención de la ley 20744- LCT en su artículo 177 y es la de darle al empleado/empleada el tiempo suficiente para recibir a su hijo en el seno de la familia, un tiempo como ya se ha señalado de tranquilidad, y dedicado a la adaptación de ambos centros de interés, la de los padres y la de esos niños que ingresan y conforman un nuevo grupo familiar. Las licencias por paternidad exceden el ser "hombre/mujer", "padre/madre" pues es sólo entendible si consideramos que una familia se conforma desde la gestación, la adopción, o el reconocimiento filiatorio más un tiempo nutriente rico en afectos y con la tranquilidad de saber que el estado a través de estas normativas vigentes acompañan a los "padres" sin distinción de género a cumplir este mandato constitucional y de derechos humanos de cuidar a sus hijos, asistir a sus hijos, integrar a sus hijos, formar familias..." Sentencia publicada en el sitio web http://www.va-abogados.com.ar/licencia-por-maternidadpaternidad-equiparacion-en-el-matrimonio-igualitario/ visitado el 06/03/2018
} 
Lopes, C. Familias formadas por parejas del mismo sexo y el Codigo Civil y Comercial de la Nación. Derecho y Ciencias Sociales. Octubre 2018. № 19. (Las familias y el derecho de las familias a dos años de vigencia del Código Civil y Comercial) Pgs 22-44. ISNN 1852-2971. Instituto de Cultura Jurídica y Maestría en Sociología Jurídica. FCJ y S. UNLP

asistida a los procedimientos y técnicas realizados con asistencia médica para la consecución de un embarazo. Se trata de conseguir la unión del óvulo y el espermatozoide con la ayuda de la ciencia.

El art. 2 del Dec. 956/2013, reglamentario de la ley antes mencionada, aclara las diferencias entre técnicas de baja y alta complejidad. Se consideran técnicas de baja complejidad a aquellas que tienen por objeto la unión entre óvulo y espermatozoide en el interior del sistema reproductor femenino, lograda a través de la inducción de ovulación, estimulación ovárica controlada, desencadenamiento de la ovulación e inseminación intrauterina, intracervical o intravaginal, con semen de la pareja o donante. Se entiende por técnicas de alta complejidad a aquellas donde la unión entre óvulo y espermatozoide tiene lugar por fuera del sistema reproductor femenino, incluyendo a la fecundación in vitro; la inyección intracitoplasmática de espermatozoide; la criopreservación de ovocitos y embriones; la donación de ovocitos y embriones y la vitrificación de tejidos reproductivos.

Como fuente filiatoria, que da origen al vínculo entre padres, madres e hijos, el acento está puesto en el deseo de ser padres o madres. Se trata de la voluntad procreacional expresada a través del consentimiento previo, informado y libre al uso de determinada técnica. Señala el art. 560 del CCyC que, al intervenir necesariamente un centro de salud en las TRHA, éste debe recabar el consentimiento previo, informado y libre de las personas que se someten al uso de las mismas, el cual debe renovarse cada vez que se procede a la utilización de gametos o embriones. Con posterioridad a la instrumentación de dicho consentimiento, de acuerdo al art. 561 del CCyC se debe proceder a su protocolización ante escribano público o certificación ante la autoridad sanitaria correspondiente. ${ }^{6}$

En cuanto a la determinación de la filiación de las personas nacidas por TRHA y conforme al art. 562 del CCyC, son hijos de quien dio a luz ( regla que no admite excepciones

\footnotetext{
${ }^{6}$ No existe hasta la fecha autoridad sanitaria designada por ley especial ante quien llevar adelante esta protocolización. A través de la Disp. 1093/2016 del Registro de las Personas de la provincia de Buenos Aires de fecha 5/5/2016, considerando que “...tal protocolización ante escribano público, deviene en el costo económico inevitable que de ello se deriva, resultando discriminatorio incurrir en dicha exigencia por parte del Estado, toda vez que se estaría conculcando el principio de igualdad y no discriminación...”, atento la calidad de funcionario público de los delegados del Registro Civil, la Directora Provincial del Registro de las Personas de ese momento dispuso "Ordenar que en las inscripciones de nacimiento ocurridas a partir de la entrada en vigencia del CCyC y cuya causa de filiación sea el empleo de TRHA; el consentimiento previo, informado y libre exigido por el artículo 561 de la norma citada, podrá ser prsentado al momento de la inscripción del nacimiento para su certificación por parte del delegado, quien otorgará fe pública al instrumento previa manifestación y ratificación ante su presencia, para su posterior archivo en calidad de documentación base de la inscripción en la delegación correspondiente..." Para ello, “...se deberá presentar el instrumento donde conste el consentimiento, el que deberá presentarse por escrito en original, con el nombre de la institución sanitaria en la que se haya practicado la TRHA, con la debida constancia de habilitación, nombre de los médicos intervinientes, y datos de las personas que se someten a la TRHA y otorgan su consentimiento..."
} 
Lopes, C. Familias formadas por parejas del mismo sexo y el Codigo Civil y Comercial de la Nación. Derecho y Ciencias Sociales. Octubre 2018. № 19. (Las familias y el derecho de las familias a dos años de vigencia del Código Civil y Comercial) Pgs 22-44. ISNN 1852-2971. Instituto de Cultura Jurídica y Maestría en Sociología Jurídica. FCJ y S. UNLP

dentro de nuestro cuerpo legal, quién da a luz tiene necesariamente vínculo filiatorio con quién nace; ya que no se admite la posibilidad de gestar para otro) y del hombre o de la mujer que también ha prestado su consentimiento previo, informado y libre; el cual, ya protocolizado, se inscribe en el Registro del Estado Civil y Capacidad de las Personas. En razón de que aquí es absolutamente independiente quién haya aportado los gametos, una vez determinada la filiación, operan las protecciones específicas ya mencionadas: la protección del derecho a la información del nacido por TRHA (arts. 563 y 564) y la protección de los vínculos jurídicos creados, en tanto el art. 577 proclama la inadmisibilidad tanto de la impugnación de la filiación de los hijos nacidos mediante el uso de TRHA cuando haya mediado consentimiento previo, informado y libre a dichas técnicas, como del reconocimiento y/o el ejercicio de acción de filiación o de reclamo alguno de vínculo filial respecto de éste.

\section{Algo de lo que queda: gestación por sustitución.}

El Anteproyecto de Reforma al CCyC contenía la regulación de la figura. Diversas razones operaron como fundamento:

En primer lugar, la fuerza de la realidad, tanto nacional como internacional. Dado que esta técnica es practicada lícitamente en varios países extranjeros, las personas que cuentan con recursos económicos viajan con esos fines (se lo conoce como "turismo reproductivo"); de hecho, muchos niños ya nacieron, y su interés superior no permite que se niegue jurídicamente la existencia de un vínculo con quien o quienes han tenido la voluntad de ser padres/madres. Más aún, en el país ya se ha planteado la impugnación de la maternidad de la gestante que dio a luz por no ser ella la titular del material genético femenino utilizado. Por otra parte, el reconocimiento legal del matrimonio de las personas del mismo sexo ha hecho necesario regular esta filiación, dado que ellas tienen derecho a recurrir a la filiación por adopción, por lo que sería inconsecuente no autorizarlas al uso de las técnicas de reproducción humana asistida. Finalmente, se entiende que es más beneficioso contar con una regulación con pautas claras, previamente fijadas, que brinden seguridad jurídica tanto a los usuarios de estas técnicas como, principalmente, a los niños nacidos de ellas; ni la postura abstencionista ni la prohibitiva podrán evitar que se presenten conflictos jurídicos complejos que deberán ser resueltos a pesar de vacío legislativo o su expresa prohibición" (Fundamentos del CCyC, pág. 570).

De esta forma, el Anteproyecto permitía la gestación por sustitución previéndose un proceso judicial con reglas propias que culminaría con una decisión de autorización para la que, conforme el art. 562 de esa versión, se requería: a) capacidad de quién llevaba adelante el embarazo, b) consentimiento informado por parte de todos los intervinientes con la debida preparación; c) que la gestante portara material genético de uno o ambos miembros de los 
Lopes, C. Familias formadas por parejas del mismo sexo y el Codigo Civil y Comercial de la Nación. Derecho y Ciencias Sociales. Octubre 2018. № 19. (Las familias y el derecho de las familias a dos años de vigencia del Código Civil y Comercial) Pgs 22-44. ISNN 1852-2971. Instituto de Cultura Jurídica y Maestría en Sociología Jurídica. FCJ y S. UNLP

comitentes y no de ella; d) la demostración de la imposibilidad de concebir o llevar adelante a término un embarazo por parte de los comitentes; e) que la gestante no haya recibido retribución, f) que la gestante no se hubiera sometido a un proceso de gestación por sustitución más de dos veces; g) que la gestante hubiese parido con anterioridad, al menos, un hijo propio.

Los requisitos tenían por objeto obtener certeza de que la mujer que presta su cuerpo lo hace libremente y que este recurso no es usado como un mero capricho por los comitentes, sino como última alternativa (Fundamentos del CCyC, pág. 571). La figura fue eliminada del texto legal durante el debate legislativo. El origen de la exclusión puede leerse en el predictamen de la Comisión Bicameral para la Reforma, Actualización y Unificación de los Códigos Civil y Comercial de la Nación, elaborado en Noviembre de 2013, en el cual se señala:

"La gestación por sustitución es la figura jurídica dentro del Libro Segundo sobre "Relaciones de Familia" que más voces encontradas ha generado. Sucede que es un proceso especial de técnicas de reproducción asistida que compromete a tres personas y no a dos, para alcanzar la maternidad/paternidad. Es decir, una tercera persona con quien no se tendrá vínculo filial alguno. La especialidad y mayor complejidad de esta técnica de reproducción humana deriva del propio texto legal proyectado, siendo este tipo de práctica médica la única que involucraba un proceso judicial previo con la previsión de cumplir varios elementos o requisitos para la viabilidad de la acción judicial. En este sentido, la gestación por sustitución encierra dilemas éticos y jurídicos de gran envergadura que ameritaría un debate más profundo de carácter interdisciplinario. En este contexto de incertidumbre y cuasi silencio legal en el derecho comparado, se propone de manera precautoria, eliminar la gestación por sustitución del proyecto de reforma."’

Sin embargo, la falta de regulación, no ha impedido que antes o después del nuevo Código las personas acudan a la figura para concretar su deseo de ser padres o madres. Por un lado en el exterior, en aquellos países que sí contienen regulación específica, pero fundamentalmente en nuestro país, utilizando distintas herramientas legales para permitir que coincida el vínculo jurídico del niño que nace con la o las personas que tenían la voluntad procreacional (NOTRICA, 2018). ${ }^{8}$

Es así que poseen trámite parlamentario distintos proyectos de ley que tienen por objeto la modificación del nuevo Código, incluyendo la gestación por sustitución entre las TRHA

\footnotetext{
${ }^{7}$ Publicado en: http://www.parlamentario.com/noticia-67689.html,

${ }^{8}$ NOTRICA $(2018,111)$. En este trabajo el autor señala que al momento de su redacción existían " 28 sentencias dictadas en los tribunales nacionales de diferentes procedimientos llevados a cabo en nuestro territorio nacional y a tres años de la entrada en vigor el Código Civil y Comercial aprobado sin una regulación de la GS, la realidad nos sigue poniendo en jaque. Se requiere una legislación que regule la práctica, porque cada vez son más los casos que se conocen y el Estado debe estar a la altura de las circunstancias".
} 
Lopes, C. Familias formadas por parejas del mismo sexo y el Codigo Civil y Comercial de la Nación. Derecho y Ciencias Sociales. Octubre 2018. № 19. (Las familias y el derecho de las familias a dos años de vigencia del Código Civil y Comercial) Pgs 22-44. ISNN 1852-2971. Instituto de Cultura Jurídica y Maestría en Sociología Jurídica. FCJ y S. UNLP

que permiten alcanzar la maternidad/paternidad. Se trata de una técnica de particular importancia para hombres solos o parejas de hombres, existiendo en el país antecedentes jurisprudenciales que han reconocido ese particular escenario para autorizar la práctica. ${ }^{9}$

Se estima que la mayor certeza para todas las partes se consigue a través de una legislación certera, que defienda los derechos de las personas involucradas y brinde claridad respecto a los lugares que cada uno ocupa.

Esta certeza puede obtenerse a través de la reforma normativa, en función de la regulación de la práctica. Sin embargo, la carencia de regulación no es óbice para obtener algo de certeza por otros medios.

Es ello lo que ha buscado el amparo colectivo iniciado por el Defensor del Pueblo de C.A.B.A., la FALGBT, y los señores DR y GGSM, mediante el cual se está requiriendo la inscripción de los niños y niñas que nacidos por la TRHA que denominan como "gestación solidaria" conforme el consentimiento previo, libre e informado expresado por él/la, los/as comitente/s con voluntad procreacional, sin establecer vínculo filiatorio con la persona gestante sin voluntad procreacional, declarándose la inconstitucionalidad de toda norma que impida o vulnere el derecho a la identidad de niños y niñas pertenecientes a dicho universo colectivo.

En ese marco, en Agosto de 2017 la Sala I de la Cámara de Apelaciones en lo Contencioso, Administrativo y Tributario de C.A.B.A. accedió cautelarmente al pedido resolviendo:

“...conceder la tutela preventiva requerida, aunque -cabe adelantar- con un alcance diferente al solicitado. En efecto, a fin de resguardar acabadamente -durante el tiempo que demande la sustanciación de esta causa- los derechos de los menores alcanzados por la medida cautelar, en particular, el derecho a la identidad y todos los derechos que por añadidura les competen, cabe hacer lugar a la tutela preventiva ordenando que el Registro inscriba en términos preventivos a los menores nacidos por técnicas de reproducción humana asistida de alta complejidad realizada en el país, denominada gestación solidaria, conforme el consentimiento previo, libre e informado expresado por los progenitores con voluntad procreacional, sin emplazar como progenitor a la persona gestante cuando -previa y fehacientemente- hubiera expresado no tener voluntad procreacional. No obstante lo expuesto, se ordena provisionalmente -con sustento en el art. 184, CCAyT- que los datos de la gestante sean debidamente asentados -a fin de respetar el derecho a la identidad de los niños y niñas pertenecientes a dicho universo - en el legajo perteneciente a cada

\footnotetext{
${ }^{9}$ Entre ellos, Trib. Coleg. Familia No 5 de Rosario, 27/5/2016, autos: SGG y otros s/ filiación publicado en RDF - 2017 I-121; Juzg. Flia. Viedma; 06/07/2017, autos "RESERVADO S/ AUTORIZACION JUDICIAL (f)", Expte $\mathrm{N}^{\mathrm{o}}$ 0260/17/J7, disponible online en http://www.diariojudicial.com/nota/78740/civil/subrogacionigualitaria.html visitada el 29/08/2018.
} 
Lopes, C. Familias formadas por parejas del mismo sexo y el Codigo Civil y Comercial de la Nación. Derecho y Ciencias Sociales. Octubre 2018. № 19. (Las familias y el derecho de las familias a dos años de vigencia del Código Civil y Comercial) Pgs 22-44. ISNN 1852-2971. Instituto de Cultura Jurídica y Maestría en Sociología Jurídica. FCJ y S. UNLP

uno de ellos (cf. art. 563, CCyCom).”( Cám. Ap. Cont. Adm. Trib. Sala I C.A.B.A. Agosto de 2017 en autos "DEFENSOR DEL PUEBLO DE LA CIUDAD AUTONOMA DE BUENOS AIRES Y OTROS CONTRA GCBA y otros SOBRE AMPARO)

\section{La cobertura de TRHA a parejas del mismo sexo.}

El acceso a una de las TRHA expresamente reconocidas en el CCyC, como camino para acceder a la progenitura, puede enfrentar a quien o quienes deciden su utilización a la imposibilidad de sufragar los costos económicos que ello demande, configurándose uno de los obstáculos más importantes a la hora de elegir este proyecto parental. En ese entendimiento, en el año 2013 se sancionó la Ley 26.862 que tiene por objeto garantizar el acceso integral a los procedimientos y técnicas médico-asistenciales de reproducción médicamente asistida. ${ }^{10}$

\section{El art. 7 señala los beneficiarios:}

Tiene derecho a acceder a los procedimientos y técnicas de reproducción médicamente asistida, toda persona mayor de edad que, de plena conformidad con lo previsto en la ley 26.529 , de Derechos del paciente en su relación con los profesionales e instituciones de la salud, haya explicitado su consentimiento informado. El consentimiento es revocable hasta antes de producirse la implantación del embrión en la mujer.

La cobertura se asienta en el derecho individual de toda persona de poder gozar de las posibilidades que los adelantos científicos ofrecen para concretar su deseo parental. GIL DOMINGUEZ $(2013,24)$ ha sostenido que

si bien se ha manifestado hasta el hartazgo que las personas no titularizan un derecho a tener un hijo o hijos desde posturas amarradas a un cierto orden natural de las cosas que desconoce el deseo y la subjetividad como un elemento determinante de la constitución subjetiva, lo cierto es, que sí

\footnotetext{
${ }^{10}$ Señala el art. $8^{\circ}$ de la Ley en cuanto a la cobertura: "El sector público de salud, las obras sociales enmarcadas en las leyes 23.660 y 23.661, la Obra Social del Poder Judicial de la Nación, la Dirección de Ayuda Social para el Personal del Congreso de la Nación, las entidades de medicina prepaga y las entidades que brinden atención al personal de las universidades, así como también todos aquellos agentes que brinden servicios médicoasistenciales a sus afiliados independientemente de la figura jurídica que posean, incorporarán como prestaciones obligatorias y a brindar a sus afiliados o beneficiarios, la cobertura integral e interdisciplinaria del abordaje, el diagnóstico, los medicamentos y las terapias de apoyo y los procedimientos y las técnicas que la Organización Mundial de la Salud define como de reproducción médicamente asistida, los cuales incluyen: a la inducción de ovulación; la estimulación ovárica controlada; el desencadenamiento de la ovulación; las técnicas de reproducción asistida (TRA); y la inseminación intrauterina, intracervical o intravaginal, con gametos del cónyuge, pareja conviviente o no, o de un donante, según los criterios que establezca la autoridad de aplicación. Quedan incluidos en el Programa Médico Obligatorio (PMO) estos procedimientos, así como los de diagnóstico, medicamentos y terapias de apoyo, con los criterios y modalidades de cobertura que establezca la autoridad de aplicación, la cual no podrá introducir requisitos o limitaciones que impliquen la exclusión debido a la orientación sexual o el estado civil de los destinatarios. También quedan comprendidos en la cobertura prevista en este artículo, los servicios de guarda de gametos o tejidos reproductivos, según la mejor tecnología disponible y habilitada a tal fin por la autoridad de aplicación, para aquellas personas, incluso menores de dieciocho (18) años que, aun no queriendo llevar adelante la inmediata consecución de un embarazo, por problemas de salud o por tratamientos médicos o intervenciones quirúrgicas puedan ver comprometidas su capacidad de procrear en el futuro."
} 
Lopes, C. Familias formadas por parejas del mismo sexo y el Codigo Civil y Comercial de la Nación. Derecho y Ciencias Sociales. Octubre 2018. № 19. (Las familias y el derecho de las familias a dos años de vigencia del Código Civil y Comercial) Pgs 22-44. ISNN 1852-2971. Instituto de Cultura Jurídica y Maestría en Sociología Jurídica. FCJ y S. UNLP

existe nítidamente el derecho que titulariza toda persona de poder intentar concebir un hijo mediante las posibilidades que la ciencia ofrezca.

En idéntico sentido, la Corte Interamericana de Derechos Humanos sostuvo en el año 2012 que "el derecho a la vida privada se relaciona con: i) la autonomía reproductiva, y ii) el acceso a servicios de salud reproductiva, lo cual involucra el derecho de acceder a la tecnología médica necesaria para ejercer ese derecho" $"$. Desde este enfoque, pierden toda virtualidad aquellas argumentaciones que partían de la idea de que el acceso a las TRHA era la respuesta adecuada a una enfermedad y, en ese marco, corresponde su cobertura.

Tal es lo que acontece, como ejemplo, con la Ley 14.208 de la provincia de Buenos Aires, cuyo origen tuvo en miras el reconocimiento de la infertilidad humana como enfermedad como así también el reconocimiento de la cobertura médico asistencial integral de las prácticas médicas a través de las técnicas de fertilización asistida. Sucede que la propia ley define a la infertilidad como "la dificultad de una pareja de concebir un niño naturalmente o de llevar un embarazo a término, luego de un año de vida sexual activa" (art. $2^{\circ}$ ). De acuerdo a lo expuesto, suele negarse ilegalmente la cobertura de TRHA a parejas de mujeres (o mujeres solas) argumentando ausencia de patología, pudiendo concebir al niño naturalmente en el marco de la vida sexual activa.

En oportunidad de expedirse al respecto la Justicia, se ha sostenido que en estos casos se verifica una situación aún más extrema que la mera 'dificultad' de la pareja para concebir un niño naturalmente, pues lo que hay es una manifiesta imposibilidad fisiológica de procrear naturalmente de las parejas homosexuales. Y, en la sentencia, continúan disponiendo

"No es un razonamiento válido argumentar que la amparista podría, en teoría, ser fisiológicamente apta para concebir un niño naturalmente con la intervención de un tercero masculino, puesto que la ley establece expresamente que la dificultad (en el presente caso, imposibilidad) debe ser "de la pareja" (y no meramente individual), estando vedado para toda interpretación legal o normativa hacer distingos discriminatorios por tratarse de una pareja del mismo sexo. De hecho, el único modo en que una mujer homoafectiva podría ejercer su inviolable derecho a la maternidad sin acudir a la asistencia de la técnica de reproducción asistida reclamada por la amparista, sería modificando su orientación sexual, lo cual el ordenamiento jurídico jamás podría exigir sin con ello violentar de un modo anacrónico y tiránico los derechos personalísimos del ser humano..."( TOC 2 de Azul, 13/11/2015, "XXX c/ Instituto Obra Médico Asistencial (I.O.M.A. s/ Acción de Amparo")

\footnotetext{
11 CIDH, 28/11/2012, Caso Artavia Murillo y otros ("Fecundación In Vitro") Vs. Costa Rica, párr. 146;
} sentencia publicada en el sitio web de la Corte Interamericana de Derechos Humanos: http://corteidh.or.cr 
Lopes, C. Familias formadas por parejas del mismo sexo y el Codigo Civil y Comercial de la Nación. Derecho y Ciencias Sociales. Octubre 2018. № 19. (Las familias y el derecho de las familias a dos años de vigencia del Código Civil y Comercial) Pgs 22-44. ISNN 1852-2971. Instituto de Cultura Jurídica y Maestría en Sociología Jurídica. FCJ y S. UNLP

La sentencia termina resolviendo favorablemente el amparo, disponiendo que la denegación por parte del I.O.M.A. de la cobertura integral de la TRHA ha sido resuelta de forma arbitraria, a espaldas de la legislación vigente y en franca violación del derecho de la pareja a formar una familia (con independencia de la orientación sexual), que encuentra amparo en los distintos Tratados de Derechos Humanos, la Constitución Nacional y las leyes vigentes en la materia.

\section{Ejercicio de la responsabilidad parental:}

En la materia, los cambios son variados y en distintos sentidos (LOPES, 2015), excediendo su abordaje el objetivo del presente trabajo. Interesa, por tanto, destacar una de las reglas expresamente contenidas en el texto del nuevo Código de trascendental importancia que guía el proceso de determinación judicial del cuidado personal de los hijos. Establece el art. art. 656 como principio general:

...Cualquier decisión en materia de cuidado personal del hijo debe basarse en conductas concretas del progenitor que puedan lesionar el bienestar del niño o adolescente no siendo admisibles discriminaciones fundadas en el sexo u orientación sexual, la religión, las preferencias políticas o ideológicas o cualquier otra condición.

Se trata de una garantía antidiscriminatoria que, sobre el tema, ha tenido desarrollo en el Sistema Interamericano de Derechos Humanos. En el año 2012, la Corte Interamericana de Derechos Humanos condenó al Estado de Chile como responsable de la violación de los arts. 8.1, 11.2, 17.1 y 24 en relación con los arts. 1 y 19.1 de la Convención Americana sobre Derechos Humanos, en perjuicio de la Sra. K.A.R. y sus hijas. Se trataba de un caso donde, por la orientación sexual de la madre, la justicia chilena dispuso el cambio de la tenencia de tres niñas a favor de su padre. ${ }^{12}$

En el mismo sentido que el art. 656 del CCiv. y Com., la Corte Interamericana sostuvo que

“...la determinación del interés superior del niño, en casos de cuidado y custodia de menores de edad se debe hacer a partir de la evaluación de los comportamientos parentales específicos y su impacto negativo en el bienestar y desarrollo del niño según el caso, los daños o riesgos reales y probados, y no especulativos o imaginarios. Por tanto, no pueden ser admisibles las especulaciones, presunciones, estereotipos o consideraciones generalizadas sobre características personales de los padres o preferencias culturales respecto a ciertos conceptos tradicionales de la familia ... la sola referencia al mismo [interés superior del niño] sin probar, en concreto, los

\footnotetext{
${ }^{12}$ Cuarta sala de la Corte Suprema, Santiago, 31/05/ 2004, Justicia y derechos del niño Nro. 8, Ed. UNICEF,
} Sgo. de Chile 2006, p. 198 y ss. 
Lopes, C. Familias formadas por parejas del mismo sexo y el Codigo Civil y Comercial de la Nación. Derecho y Ciencias Sociales. Octubre 2018. № 19. (Las familias y el derecho de las familias a dos años de vigencia del Código Civil y Comercial) Pgs 22-44. ISNN 1852-2971. Instituto de Cultura Jurídica y Maestría en Sociología Jurídica. FCJ y S. UNLP

riesgos o daños que podrían conllevar la orientación sexual de la madre para las niñas, no puede servir de medida idónea para la restricción de un derecho protegido como el de poder ejercer todos los derechos humanos sin discriminación alguna por la orientación sexual de la persona . El interés superior del niño no puede ser utilizado para amparar la discriminación en contra de la madre o el padre por la orientación sexual de cualquiera de ellos...”. (Corte Interamericana de Derechos Humanos, Caso Atala Riffo y Niñas vs. Chile, párr.. 109 y 110)

Como puede observarse, en el fallo se formuló una determinación del interés superior del niño para el caso concreto sustentado en hechos objetivos a fin de no caer en apreciaciones personales, circunstancia que no había ocurrido en la sentencia chilena.

\section{Conclusiones}

Sin ánimo de ser definitivas, hasta aquí algunas pinceladas del escenario en el que las parejas del mismo sexo podrían estar tomando decisiones en torno a su propia organización familiar en nuestro país. El camino recorrido para llegar a este punto fue arduo y espinoso, es posible que siga siéndolo.

Sin embargo, el texto del CCyCN con su impronta de ser conteste con el Derecho Internacional de los Derechos Humanos garantiza que la lucha por la conquista y defensa de derechos se desarrolle en términos de mayor igualdad de condiciones y oportunidades, posibilitando que nuevas situaciones encuentren respuesta o dejando en evidencia la falta de solución a otras.

Además, el avance normativo hacia la legitimación de distintos proyectos familiares desafía la posibilidad de construir otros nuevos y distintos que reclamarán también su reconocimiento. En definitiva, como hasta aquí, continuará siendo la realidad la que nos indique los rumbos que asumen, día a día, las familias y los derechos. Y será la fuerza de esa realidad la que continúe erosionando prejuicios, representaciones y dogmas a fin de avanzar hacia el reconocimiento pleno de que, la diversidad y la pluralidad, posibilitan que las familias y sus integrantes transiten sus vidas con mayor igualdad.

Porque como escribía hace unos años GUERRA:

Para que la familia entre en crisis en el mejor de los sentidos, (como apertura ideológica respetuosa de las múltiples maneras de vivir, construir y habitar las comunidades denominadas familias) en nuestra sociedad no tendría que haber desigualdades de género, etnia, clase, orientación sexual, nacionalidad y edad. Para deshacernos de un orden heteronormativo que violenta nuestros cuerpos resulta indispensable y urgente subvertir nuestra realidad cotidiana. 
Lopes, C. Familias formadas por parejas del mismo sexo y el Codigo Civil y Comercial de la Nación. Derecho y Ciencias Sociales. Octubre 2018. № 19. (Las familias y el derecho de las familias a dos años de vigencia del Código Civil y Comercial) Pgs 22-44. ISNN 1852-2971. Instituto de Cultura Jurídica y Maestría en Sociología Jurídica. FCJ y S. UNLP

\section{Referencias bibliográficas}

Código Civil y Comercial de la Nación.(2012) Fundamentos. Ed. Rubinzal-Culzoni, Santa Fé. Andriola, K. y Lopes, C. (2018).El derecho de las familias ante las nuevas formas de familia: Los desafíos ante la diversidad sexual y los vínculos afectivos. Congreso Internacional de Derecho de las Familias, Niñez y Adolescencia, Recuperado de http://congresoderechofamiliasmendoza.com/wpcontent/uploads/2018/07/Andriola.Lopes_.-1.-.pdf [ 28-08-2018].

Cadoret A. (2003). Padres como los demás. Homosexualidad y parentesco. Madrid. Ed. Gedisa.

De La Torre, N. (2017). La gestación por sustitución "hecha en casa": el primer reconocimiento jurisprudencial en parejas del mismo sexo. Comentario al fallo Trib. Coleg. Familia No 5 de Rosario, 27/5/2016, autos: SGG y otros s/ filiación. Revista de Derecho de Familia 2017-I (febrero 2017). Buenos Aires. Abeledo Perrot. Pág. 128

Gil Domínguez, A.(2012). Comaternidad y copaternidad igualitaria. Buenos Aires. La Ley. Tomo B, pág. 1251

Gil Domínguez, A.( (2013). La ley de Acceso Integral a los Procedimientos y Técnicas Médico Asistenciales de Reproducción Humana Asistida: sus proyecciones constitucionales y convencionales. Revista Derecho de Familia y Persona. Buenos Aires. La Ley. Año V, No 7, Agosto.

Gil Domínguez, A.( (2016). La triple filiación y el Código Civil y Comercial. Revista de Derecho de Familia Nro. 74. Buenos Aires. Abeledo Perrot. 2016.

De Lorenzi, M. (2017). La aritmética de la filiación: cuando no hay dos sin tres, pero tres son multitud. El imperativo real de la pluriparentalidad. $R D F 79$ - 2017 - 253.

Fernandez, S. E. y Herrera, M. (2018). Uno más uno tres. La adopción como fuente de la pluriparentalidad. Revista de Derecho de Familia. Buenos Aires. Abeledo Perrot. Nro. 83, pág. 145 y ss

Guerra L. (2010); Familia y heteronormatividad. Revista Argentina de Estudios de Juventud, [S.1.], n. 1, jul. 2010. ISSN 1852-4907.Recuperado en:http://perio.unlp.edu.ar/ojs/index.php/revistadejuventud/article/view/1477 [29/08/2018]. 
Lopes, C. Familias formadas por parejas del mismo sexo y el Codigo Civil y Comercial de la Nación. Derecho y Ciencias Sociales. Octubre 2018. № 19. (Las familias y el derecho de las familias a dos años de vigencia del Código Civil y Comercial) Pgs 22-44. ISNN 1852-2971. Instituto de Cultura Jurídica y Maestría en Sociología Jurídica. FCJ y S. UNLP

Herrera, M (2014). Comentario al art. 558 en Kemelmajer de Carlucci, A. , Herrera, M., Lloveras, N. (dir.) Tratado de Derecho de Familia según el Código Civil y Comercial. Tomo II. Santa Fé. Rubinzal-Culzoni. Pág. 456.

Jelin, E. Familias un modelo para desarmar. En Faur, E. (compiladora). Mujeres y varones en la Argentina de hoy. Géneros en movimiento. Siglo XXI y Fundación Osde. Buenos Aires. 2017. Pág. 51-73

Kemelmajer de Carlucci, A.; Herrera, M. y Lamm, E. (2010). Filiación y homoparentalidad. Luces y sombras de un debate incómodo y actual. Buenos Aires. La Ley, Buenos Aires. Tomo E, pág. 977.

Lopes, C. y Pietra, M. L. (2005). Patria potestad ejercida por padres homosexuales. Niños, menores e infancias, Revista virtual del Instituto de Derechos del Niño de la Facultad de Ciencias Jurídicas y Sociales, $N^{\circ} 3$ (UNLP)

Lopes C.(2005). Adopción por homosexuales. Anales. Revista de la Facultad de Ciencias Jurídicas y Sociales (UNLP). La Ley. Buenos Aires. Año 3, № 36, págs. 248/254.

Lopes C (2015). Responsabilidad parental en Chechile A. M. (dir.). Derecho de Familia conforme al nuevo Código civil y Comercial de la Nación. Abeledo Perrot. Buenos Aires. P. 495 y ss.

Notrica F. P. (2018). Las diversas estrategias legales en los procesos de gestación por sustitución. El trabajo artesanal de los abogados debido a la falta de regulación. Revista de Derecho de Familia. Buenos Aires. Abeledo Perrot. Nro. 2018-IV, pág. 111.

\section{Jurisprudencia en el orden que fue citada en el cuerpo del texto}

Juzgado de $1^{\text {a }}$ Instancia Contencioso Administrativo y Tributario. $\mathrm{N}^{\mathrm{o}} 4$ de C.A.B.A.:"M. del

P. C. y otra c. GCBA”, de fecha 07/04/2011. Cita on line AR/JUR/15967/2011.

Juzgado de Familia Nro 4 de Córdoba, “ASG c/ MVS y Otro s/ Medidas urgentes”, de fecha 28/06/2010. Revista de Derecho de Familia 2011 -I, Abeledo Perrot, Bs.. As. 2011, p. 137.

Juzgado de Familia Nro. 2 Mar del Plata, sentencia (no firme) inédita de fecha 24/11/2017 dictada en autos C.M.F. y otros S/ MATERIA A CATEGORIZAR (Expte MP-278862016).

Juzgado de Familia Nro. 4 La Plata, 20/02/2017, BAJM s/ adopción acciones vinculadas, Inédito. 
Lopes, C. Familias formadas por parejas del mismo sexo y el Codigo Civil y Comercial de la Nación. Derecho y Ciencias Sociales. Octubre 2018. № 19. (Las familias y el derecho de las familias a dos años de vigencia del Código Civil y Comercial) Pgs 22-44. ISNN 1852-2971. Instituto de Cultura Jurídica y Maestría en Sociología Jurídica. FCJ y S. UNLP

Cámara de Apelaciones Contencioso Administrativo y Tributario, Sala I de C.A.B.A. en autos “DEFENSOR DEL PUEBLO DE LA CIUDAD AUTONOMA DE BUENOS AIRES Y OTROS CONTRA GCBA y otros SOBRE AMPARO, de fecha, agosto de 2017 disponible online en http://www.diariojudicial.com/nota/78928 visitado el 29/08/2018.

Tribunal Oral en lo Criminal de Azul: “XXX c/ Instituto Obra Médico Asistencial (I.O.M.A. s/ Acción de Amparo", de fecha 13/11/2015, publicada en http://colectivoderechofamilia.com/wp-content/uploads/2016/03/FA.-PCIAL.TRIBUNAL-N\%C2\%BA2-AZUL.-PROV.-BS.-AS.-Cobertura-TRHA.-Pareja-demujeres.pdf, visitado el 06/03/2018.

Corte Interamericana de Derechos Humanos, , Caso Atala Riffo y Niñas vs. Chile, párr.. 109 y 110; de fecha 24/02/2012. Disponible en http://corteidh.or.cr 